\title{
CAUDA EQUINA AND LUMBAR NERVE ROOT COMPRESSION IN PATIENTS WITH AIDS
}

\author{
E. J. P. CRAWFURD, P. R. E. BAIRD, A. L. CLARK \\ From St Stephen's Hospital, London
}

\begin{abstract}
Five patients known to be HIV (human immunodeficiency virus)-positive - that is, susceptible to AIDS presented with symptoms initially thought to be indicative of lumbar disc lesions. Signs of nerve root or cauda equina compression were found in all five patients. Lumbar radiculography and, in one patient, computerised tomography produced no evidence of compressive pathology. We recommend that orthopaedic surgeons exercise caution in diagnosing nerve root compression in patients who may be HIV-positive.
\end{abstract}

Accumulating evidence about the acquired immunodeficiency syndrome (AIDS) has revealed that the disease may present with complex neurological symptoms (Britton and Miller 1984; Levy, Bredesen and Rosenblum 1985). Although most of the significant neurological features are attributable to intra-cranial disease, when the spinal cord is involved the symptoms may mimic those of cauda equina syndrome or lumbar nerve root compression.

This report describes five patients known to be HIV-positive who were referred to an orthopaedic consultant with features of lumbar spinal disease. Investigations before referral included a lumbar puncture with CSF analysis and cytology; infection had been excluded by VDRL, cryptococcal antigen, toxoplasma dye, and mycobacterial latex antigen tests as well as routine microscopy and culture of CSF. The patients were then investigated by lumbar radiculography and, in one case, by computerised tomography. These investigations and results are discussed in the context of other published reports about the neurological complications of AIDS.

\section{CASE REPORTS}

Case 1. A 37-year-old man presented with paraesthesia in both legs of three days' duration. On examination he was pyrexial with erythema multiforme affecting his trunk and limbs.

He had no appreciation of light-touch or pinprick below both iliac spines, his legs were very weak and he

E. J. P. Crawfurd, FRCS, Orthopaedic Registrar

P. R. E. Baird, FRCS, Orthopaedic Consultant

A. L. Clark, MB BS, Research Senior House Officer

Westminster Hospital, Dean Ryle Street, Horseferry Road, London SWIP 2AP, England.

Requests for reprints should be sent to Mr E. J. P. Crawfurd. (C) 1987 British Editorial Society of Bone and Joint Surgery $0301-620 \times / 87 / 1072 \$ 2.00$ subsequently developed urinary incontinence. Although acute spinal cord compression was suspected, emergency myelography showed no evidence of this; CSF cultures were all negative.

He was started on a course of intravenous phosphonoformate and, within 24 hours, his pyrexia had settled and he regained strength in his legs. Over the following week he regained bladder control and normal sensation in his legs. He was discharged home at the end of the third week and has remained well since. This episode was his first symptom of AIDS; more recently he has had opportunistic infections, despite being on prophylactic co-trimoxazole.

Case 2. A 48-year-old homosexual man presented with a one-year history of increasingly severe numbness on the lateral border and dorsum of the left foot. In the previous few weeks he had also experienced several episodes of incontinence.

On examination he had generalised lymphadenopathy, an unsteady gait and reduced sensation in the distribution of L5. Reflexes were present and symmetrical but he had bilateral extensor plantar responses. Vibration sense and proprioception were impaired in both feet.

A lumbar radiculogram and CT scan were normal. He was started on antimicrobial therapy, and initially his neurological symptoms improved and he regained control of his bladder. Since that time, however, there has again been some deterioration in his condition.

Case 3. A 54-year-old man presented with numbness over his buttocks, extending bilaterally to both feet. He also complained of urgency of micturition and had difficulty in knowing when his rectum was full.

On examination he was thin and had generalised lymphadenopathy; anal tone, sensation in both legs below the inguinal ligament, and the power of dorsiflexion and plantarflexion in the left ankle were all reduced. 
Within a week of admission he became incontinent of faeces and developed urinary retention. An emergency myelogram and subsequent $\mathrm{CT}$ myelogram revealed no abnormality. Despite a good initial response to antimicrobial therapy, he later had a relapse and died after two months.

Case 4. A 37-year-old man presented with a five-month history of numbness in the lateral border of the right foot, sometimes associated with pain in the same region. He also complained of low back pain and some reduced sensation in the buttocks.

On examination he was found to have absent lighttouch and pinprick sensation over the lateral border of the right foot. Reflexes were normal except for an absent right ankle jerk. There was no loss of power. His WBC was $2.9 \times 10^{9} / 1$.

Lumbar radiculography was normal and antimicrobial therapy was given. One week later he developed bilateral weakness of ankle inversion and eversion, and also lost the left ankle jerk. After minor improvement in his symptoms he went on to develop cerebral oedema and died.

Case 5. A 48-year-old man admitted for the investigation of headaches was found on examination to have difficulty in walking. He had previously been found to be HIV-positive. Examination revealed a right foot drop with complete loss of dorsiflexion but no sensory loss. There was no limitation of straight-leg raising or other signs of nerve root compression. No cause was found for the foot drop, and his condition remains unchanged.

\section{DISCUSSION}

Each patient was initially referred with a suspected diagnosis of cauda equina or nerve root compression. Because the symptoms and signs were highly suggestive of lumbar disc lesions, all the patients were investigated by myelography; one also had CT-enhanced myelography. However, these investigations failed to show significant disc protrusion or any other compressive pathology.

All the patients made an initial recovery on antimicrobial therapy; the agents used varied from case to case but each one received sodium phosphonoformate and a combination of broad-spectrum antibiotics. One patient with a systemic fungal infection was also given flucytosine and ketoconazole. Although no definite cause of these symptoms was found, it is postulated that these patients developed a transverse myelitis, possibly due to the HIV itself, as no other pathogen was found despite extensive investigation. Marwick (1985) has suggested that myelitis might be due to an opportunistic infection by toxoplasma but no evidence to this effect was found. Unfortunately, due to the possible risk of infection, postmortem examination of AIDS patients has remained very limited.

Neurological abnormalities have been frequently described in HIV-related disease. It would seem that about $30 \%$ of patients with AIDS in San Francisco had a significant neurological abnormality, the neurological disturbance being the initial complaint in $10 \%$ of these cases. However, in that series the most common neurological presentations were encephalitis (39 cases) and meningitis (17 cases). It seems unlikely that either of these diagnoses was relevant in the present series. Britton and Miller (1984) noted that transverse myelitis is a rare complication of AIDS, but also stated that the clinical and pathological features of this aspect of the disease are unclear and have yet to be documented.

In the present series, muscle weakness was a feature in all patients, generally affecting the muscles supplied by the fifth lumbar and first sacral nerve roots more severely than those supplied by the third and fourth lumbar roots. In one patient the signs were entirely confined to the fifth lumbar distribution. Four patients complained of numbness and had reduced sensation, the distribution of the sensory loss correlating poorly with anatomical dermatomes. On presentation two patients had urinary incontinence, and a third became incontinent of faeces. Peripheral neurological symptoms have been described by Snider et al. (1983) who found that eight of their 50 patients with neurological symptoms had evidence of peripheral neuropathy. Of these, six patients had a reduced or absent ankle jerk, and distal weakness was prominent in two.

Petito et al. (1985) undertook 89 consecutive postmortems on AIDS patients; they found that 20 had microscopic evidence of vacuolar myopathy and that 12 of these 20 had had symptoms attributable to spinal cord lesions during life. Although the authors described the microscopic appearances, their findings were not discussed in detail and the aetiology of the myopathy remains obscure.

Extensive research into AIDS continues to reveal its protean nature, especially its neurological manifestations, and the syndrome must be considered in the differential diagnosis of patients presenting with features of spinal cord compression.

The authors would like to thank Dr B. Gazzard, the consultant in charge of these cases.

\section{REFERENCES}

Britton CB, Miller JR. Neurologic complications in acquired immunodeficiency syndrome (AIDS). Neurol Clin 1984:2:315-39.

Levy RM, Bredesen DE, Rosenblum ML. Review article. Neurological manifestations of the acquired immunodeficiency syndrome (AIDS): experience at UCSF and review of the literature $J$ Neurosurg 1985:62:475-95.

Marwick C. Neurological complications appear often in AIDS. JAMA $1985 ; 253: 3379$ and 3383 .

Petito CK, Navia BA, Cho E-S, Jordon BD, George DC, Price RW. Vacuolar myelopathy pathologically resembling subacute combined degeneration in patients with the acquired immunodeficiency syndrome. N Engl J Med 1985:312:874-9.

Snider WD, Simpson DM, Nielson S, Gold JW, Metroka CE, Posner JB. Neurological complications of acquired immunodeficiency syndrome: analysis of 50 patients. Ann Neurol 1983;14:403-18. 